\title{
INFÂNCIA E CONHECIMENTO ESCOLAR: PRINCÍPIOS PARA A CONSTRUÇÃO DE UMA EDUCAÇÃO FÍSICA "PARA" E "COM" AS CRIANÇAS
}

\author{
José Alfredo Debortoli* \\ Meily Assbú Linhales ** \\ Tarcísio Mauro VAGO $* * *$
}

\section{RESUMO}

Neste artigo tratamos do ensino escolar da Educação Física para as crianças, ancorando nossa reflexão nos projetos de ensino, pesquisa e extensão universitária que realizamos como docentes no curso de Educação Física da UFMG. Num primeiro momento abordamos a Educação Física como área de conhecimento escolar; depois, apresentamos questões relativas à formação de professores, identificando dilemas e necessidades de intervenção e, como último ponto, ressaltamos alguns aspectos relativos à infância, aqui entendida como construção sociocultural e como um tempo singular no processo de formação humana.

PALAVRAS-CHAVE: Educação Física - Infância - Escola.

\section{INTRODUÇÃO}

\begin{abstract}
$\mathrm{A}$ s reflexões e proposições aqui apresentadas foram alimentadas nas práticas de formação que temos buscado desenvolver no cotidiano de escolas de educação infantil. Como educadores atuantes em um curso de formação de professores de Educação Física,

* Professor Assistente do Departamento de Educação Física da Escola de Educação Física, Fisioterapia e Terapia Ocupacional (EEFFTO)/Universidade Federal de Minas Gerais (UFMG), licenciado em Educação Física pela EEF/UFMG, mestre em Educação pela Faculdade de Educação (FaE)/UFMG e doutorando em Educação pela Pontifícia Universidade Católica-RJ.

* Professora Assistente do Departamento de Educação Física da EEFFTO/UFMG, licenciada em Educação Física pela EEF/UFMG, mestre em Ciência Política pela Faculdade de Filosofia e Ciências Humanas/UFMG e doutoranda em Educação pela FaE/UFMG.

***Professor Adjunto do Departamento de Educação Física da EEFFTO/UFMG, licenciado em Educação Física, mestre em Educação pela FaE/UFMG e doutor em Educação pela Faculdade de Educação/Universidade de São Paulo (USP).
\end{abstract}


especialmente na área da Educação Física escolar, optamos por construir os saberes relativos ao fazer docente e à infância no diálogo com os professores e com as crianças, concretizando assim um projeto educacional fortemente ancorado em princípios democráticos e populares. Acreditamos que a escola pública não pode seguir outro caminho senão constituir-se como tempo/espaço de inclusão, debate, construção coletiva e realização plena de direitos sociais. Ressaltamos ainda nossa proposta de estabelecer uma relação positiva entre a universidade e a escola pública e de oferecer a alunos, professores e instituições as possibilidades de construção e as estratégias de superação e enfrentamento das tensões e contradições presentes na esfera pública escolar; ou seja, não nos limitamos a identificar apenas as mazelas, os equívocos e o reprodutivismo.

A realização do direito à educação não se materializa apenas no plano legal ou no plano das boas intenções políticas. Estes são necessários, mas não suficientes. Trata-se de uma construção cotidiana, de sujeitos concretos e historicamente situados, como aqueles de quem nos fala Guimarães Rosa na sua mineiridade: "o mais importante e bonito, do mundo, é isto: que as pessoas não estão sempre iguais, ainda não foram terminadas - mas que elas vão sempre mudando. Afinam ou desafinam" (em Grande Sertão: Veredas).

Nossa capacidade de "afinar" ou "desafinar" está condicionada pelas informações contextuais. Assim sendo, as reflexões aqui organizadas guardam estreita relação com os projetos de ensino, extensão e pesquisa que desenvolvemos na área da Educação Física escolar. Também estão alicerçadas em um compromisso de articular permanentemente a universidade pública como parceira fundamental na construção de uma escola pública popular e democrática.

Para problematizar o ensino escolar da Educação Física para as crianças organizamos este texto em três partes. Trataremos inicialmente dessa disciplina como área de conhecimento escolar; depois abordaremos a formação de professores identificando dilemas e necessidades de intervenção; como terceiro e último ponto ressaltaremos alguns aspectos relacionados à infância, aqui entendida como construção sociocultural e como um tempo singular no processo de formação humana. Esperamos que essa proposta esteja 
em consonância com a realização de uma educação pública capaz de se afirmar como um direito social para todos.

\section{A EDUCAÇÃO FÍSICA É PARTE DA ESCOLA}

Pensar a presença da Educação Física na escola pressupõe a compreensão de que ela é construída $n a$ e, ao mesmo tempo, construtora $d a$ cultura escolar. Isso exige que seus professores estejam plenamente envolvidos com o projeto pedagógico da escola em que atuam, sensíveis ao diálogo crítico com a realidade social e com as crianças, com suas necessidades e seus interesses, e sempre atentos à dimensão cultural das práticas corporais de movimento.

Essas referências iniciais, quando consideradas, colaboram para o desvelamento do que tem sido a construção escolar da Educação Física e dos limites e avanços que essa história comporta. Pensar a Educação Física escolar é pensar sua prática docente e o modo como esta se incorpora à escola. A Educação Física e seus professores estão presentes na escola desde o século XIX, e esta presença se organizou em um diálogo tenso, complexo e muitas vezes contraditório com as diferentes concepções de mundo, de educação e de ser humano que acompanham a realização cotidiana da educação escolarizada.

São várias as questões pedagógicas que, ao longo das décadas de 1980 e 1990, vêm sendo destacadas e analisadas por professores de Educação Física. Os estudos e as pesquisas que se ocupam da presença dessa disciplina nos estabelecimentos de ensino investigam sua história, os métodos e processos de ensino e aprendizagem, a formação dos professores e as concepções de corpo, movimento e cultura em que estes pretendem fundamentar seu saber escolar. Outros temas são analisados de maneira sistemática, colaborando na organização de um campo disciplinar que se encontra em pleno desenvolvimento.

Também no diálogo cotidiano com professores e alunos das escolas públicas, as circunstâncias que envolvem a Educação Física afloram muitas vezes como problemas que exigem enfrentamento: o reforço nas práticas escolares da dualidade corpo-mente, materializado no isolamento pedagógico, espacial e temporal da disciplina; 
a interpretação do conhecimento atinente à Educação Física como "um saber escolar da quadra", considerado, portanto, como "de fora" da escola; ou como "saber escolar realizado no pátio" e, assim, tratado como tempo de descanso e de recomposição para novos trabalhos sérios em sala de aula; o desprezo por seu potencial educativo e formador; a demanda escolar e social por uma Educação Física considerada como sinônimo de disciplinarização e adestramento dos corpos; a esportivização das práticas corporais, que muitas vezes tenta naturalizar um aprendizado que é socialmente construído (por exemplo, tratam-se os processos de seleção e exclusão como naturais, e não como sociais); o fato de os professores reduzirem sua ação educativa à tarefa de separar times e distribuir bolas, dentre outras questões.

Problemas pedagógicos como esses não devem ser desprezados. Da mesma forma, não pode ser perdido de vista o potencial inovador e inventivo presente no trabalho de muitos professores que incorporam, ao desenvolvimento da Educação Física escolar, o compromisso com a formação humana e com a construção de uma sociedade justa e digna. Fortalecer esse movimento e colaborar na consolidação da sua legitimidade é uma intervenção possível e potencialmente capaz de envolver os professores como sujeitos de sua própria qualificação, e da qualificação de sua prática educativa.

Outro aspecto a merecer consideração é o fato de que a Educação Física escolar apresenta-se, para a grande maioria das crianças e dos jovens matriculados no sistema público de ensino, quase que como a única possibilidade de conhecimento, sistematização, vivência e problematização dos saberes relacionados às práticas corporais de movimento culturalmente organizadas. Aqui, o direito a uma Educação Física de qualidade agrega-se ao direito social à educação pública. Essa disciplina, como os demais saberes escolares, deve constituir um tempo/espaço de aprendizagem que considere: a participação de todos na reconstrução permanente da vida em sociedade, a democracia como princípio orientador das ações políticas e a cidadania como condição legítima de pertencimento à vida social.

Diante dessas questões, fica a certeza de que a Educação Física não pode ser pensada de maneira isolada, nem seus professo- 
res tratados à margem do processo educativo que organiza os sentidos e significados socioculturais da instituição escolar: "Pensar a Educação Física pressupõe pensar a escola como instituição historicamente situada e que vive hoje um rico e tenso processo de ressignificação de sua função política e social" (Linhales, 1999, p. $33)$.

Também merece menção o fato de que os ordenamentos legais promulgados para a educação escolar - a Lei de Diretrizes e Bases da Educação Nacional (LDB) de 1996, e as Diretrizes Curriculares Nacionais do Conselho Nacional de Educação, de 1997 e 1998 - desestabilizaram de forma significativa a presença da Educação Física na escola, naquilo que apontam para a autonomia das instituições escolares na organização de seus projetos políticopedagógicos. Não se trata de um "fim de sua obrigatoriedade" conforme tem sido anunciado na mídia educativa ou por segmentos corporativistas. Mas a exigência posta desde então é a de que a presença da Educação Física na escola precisa ser qualificada, sistematizada e realizada como parte indissociável da escolarização básica, considerando-se aí que "a escola tem uma dinâmica cultural específica e é nela que a educação física é constituída como disciplina" (Vago, 1999b, p. 24).

Nestes termos, para além da legalidade e/ou obrigatoriedade, a Educação Física, como área de conhecimento escolar, precisa, como já assinalou Valter Bracht, realizar a sua legitimidade, afirmar o que pode contribuir na educação escolar de crianças, jovens e adultos e como essa contribuição se pode dar. Por certo não se trata de uma construção harmônica ou linear, mas que se dá em meio a uma relação de tensão permanente entre as práticas escolares e as demais práticas sociais, que também educam (Vago, 1999a, p. 38). Tem-se aí "um campo aberto de possibilidades de intervenção por parte do professorado da Educação Física, que, ao contrário de ser subestimado, deve ser ocupado e potencializado" (Vago, 1999a, p. 39).

Partilhamos do entendimento de que a Educação Física, como área do conhecimento escolar, realiza sua prática pedagógica tendo como objeto de ensino a "cultura corporal de movimento". Nessa condição - e em integração com os diferentes conhecimentos e práticas escolares - temos o compromisso de garantir o direito de 
acesso à riqueza dos temas e conteúdos de ensino da Educação Física, especialmente sua partilha, reinvenção e reconstrução coletiva. Assumimos, assim, responsabilidades com a produção de novas sínteses, intervenções e condições necessárias para uma formação humana fundamentada em princípios de autonomia e cidadania.

\section{OS PROFESSORES DE EDUCAÇÃO FÍSICA, SUAS PRÁTI- CAS E SUAS EXPERIÊNCIAS DE FORMAÇÃO}

Sabemos que a formação de professores de Educação Física encontra-se, ainda, bastante impregnada por uma lógica instrumental que supervaloriza o desenvolvimento de competências e habilidades técnicas sustentadas pelo paradigma da aptidão físico-esportiva. Esse modelo de formação, forjado especialmente durante a década de 1970 e legitimado na escola pela Lei $n^{\circ}$. 5.692/1971 e pelo Decreto $n^{\circ}$. 69.450/1971, colaborou bastante na conformação de uma educação física escolar pouco comprometida com a formação humana e com a construção de uma escola pública crítica e democraticamente organizada pelos cidadãos que a freqüentam.

Ainda não foram superadas as representações socialmente construídas acerca dos professores de Educação Física, vistos como professores "rola-bola", descomprometidos e sem um conjunto de responsabilidades pedagógicas, professores "disciplinários" ou animadores das festas e dos torneios escolares. Essa é uma tarefa de toda a escola, e não só da Educação Física. Tais representações, com seus reducionismos, levam a um desprestígio social e educacional que demanda cuidado e divisão de responsabilidades, e requerem estratégias para a construção de um fazer pedagógico diferente destes. Como salienta Miguel Arroyo (2000),

onde não há uma visão de Educação Básica universal, de educação como direito humano, formação, não haverá possibilidade de afirmar uma cultura profissional específica. Aí está o cerne de nosso prestígio ou desprestígio social e profissional, na visão estreita ou alargada de ensino ou de educação que afirmemos. 
A atuação de professores habilitados em Educação Física em todos os níveis de escolarização do sistema de ensino só poderá ser considerada um avanço se esses profissionais estiverem em condições de participar efetivamente do projeto pedagógico escolar. A escola precisa legitimar essa participação.

A qualificação poderia incluir um programa de formação continuada capaz de envolver todos estes professores que realizam, cotidianamente, a Educação Física escolar. Poderia ainda trazer para os momentos de estudo e de reflexão os saberes relativos à prática pedagógica que se constroem na experiência vivida (Dayrell, 1996, p. 140), no diálogo com os alunos e demais sujeitos da comunidade escolar. Ninguém mais que os próprios professores sabem dos problemas enfrentados na prática escolar, e da necessidade permanente de qualificação.

Muitas vezes esses problemas e necessidades se confundem com outros, relativos às condições objetivas de trabalho no sistema público de educação, como carreira, salário, gestão escolar, materiais e equipamentos, dentre outros. Essas condições não podem ser desprezadas, ao mesmo tempo em que não podem substituir ou mascarar a necessidade de construção de um projeto político-pedagógico para o ensino da Educação Física escolar.

Tomando como ponto de partida as ponderações até aqui apresentadas, destacamos alguns princípios orientadores para a consolidação da Educação Física na educação infantil e nas séries iniciais do ensino fundamental.

A qualificação permanente é um direito dos educadores e, como tal, precisa constituir uma ação educativa capaz de identificar e enfrentar os problemas já arrolados e, ao mesmo tempo, apresentar-se como estratégia de superação das fragmentações presentes na história da educação escolar e, também, na história da Educação Física.

A fragmentação dos saberes escolares, bem como a sua conseqüente hierarquização, reduz o fazer pedagógico da Educação Física ao lugar de atividade eminentemente prática, destituída de saberes e possibilidades de reflexão. O movimentar-se humano é tratado apenas como ato motor, descontextualizado e desculturalizado. Tal fragmentação reforça a lógica dual que separa cor- 
po/mente, sensibilidade/razão, agir/pensar e prática/teoria, retirando da Educação Física elementos necessários à sua organização como área de conhecimento escolar e ao seu diálogo com os demais saberes escolares.

Outro processo de fragmentação que toca significativamente a Educação Física diz respeito aos tempos/espaços escolares. Articulados à fragmentação dos saberes, os tempos e espaços pedagógicos dessa disciplina têm sido tratados como dispositivos de compensação dos desgastes e insatisfações presentes no cotidiano escolar, promovendo na maioria das práticas a idéia de um fazer compensatório, pouco ou nada sistematizado e destituído de intencionalidade. Tempos/espaços dos quais a escola pode dispor, dispensando-os sempre e como quiser.

Por certo, todas essas fragmentações recaem sobre os sujeitos. Na verdade, é o olhar fragmentado sobre os seres humanos que produz as demais fragmentações. Ao valorizar a dimensão motora em detrimento das demais dimensões humanas, certas representações de Educação Física acabam reforçando aqueles projetos que restringem o fazer pedagógico da disciplina ao trato das aptidões física, esportiva ou do movimento corporal 'desencarnado' e descontextualizado. Alunos e professores podem, assim, perder a dimensão de totalidade necessária às experiências educativas para que as mesmas sejam significativas e capazes de estabelecer relações entre o mundo da escola e a realidade social.

Ao enfrentar esses dilemas aproximamo-nos da Educação Física que trata dos sujeitos que 'se movimentam' e, ao fazê-lo, experimentam, conhecem, problematizam e reconstroem um amplo universo de práticas corporais de movimento impregnadas de sentidos e significados socioculturais forjados pelo tempo/espaço em que se situam e que lhes confere, ou não, legitimidade na cultura escolar. Essa demarcação é fundamental no projeto curricular e nas estratégias de formação continuada. Associa-se a ela a necessidade de considerar os professores como sujeitos do conhecimento e, como tais, possuidores de saberes relativos ao fazer docente.

Assim sendo, eles devem assumir um lugar de centralidade no diálogo crítico com os saberes que vêm sendo sistematizados no campo acadêmico da Educação Física escolar, em sua articulação 
com os demais saberes e práticas escolares e em sintonia com a realidade social. Devem ainda ocupar um lugar relevante na demarcação da especificidade pedagógica da Educação Física, para que ela estabeleça parcerias em projetos coletivos de ensino sem correr o risco de diluir-se em relações de subordinação a outras áreas de conhecimento escolar. Pensar a Educação Física como a área de conhecimento escolar que trata das práticas corporais de movimento culturalmente constituídas é hoje a delimitação que melhor se articula com os projetos de mudança em curso na educação brasileira.

Os professores de Educação Física são educadores que aprendem, criam e transformam os processos de ensino-aprendizagem nos quais se inserem. As possibilidades de reflexão na e sobre a prática pedagógica só fazem sentido se estabelecidas em uma relação estreita com o cotidiano escolar e em articulação com a realidade social na qual os usos do corpo, da brincadeira, do movimentarse, do lazer e das práticas corporais ganham sentidos e significados culturais, políticos e, portanto, humanos.

\section{A EDUCAÇÃO FÍSICA E A INFÂNCIA}

Sabemos que educar crianças tomando-as como mero campo de projeções - uma "massa amorfa", um ser de natureza "ideal" e "padronizada", um projeto de "vir-a-ser" linear, ordenado e hierarquizado - não cabe mais diante dos desafios colocados para a formação humana, para uma organização escolar e pedagógica capaz de incorporar as crianças como sujeitos coletivos que devem participar de sua construção cultural e política.

Mas é bem verdade que essas representações ainda estão impregnadas no imaginário social e, em especial, nos ideários e nas práticas pedagógicas. Do casamento entre a pedagogia e a psicologia herdamos a mania de selecionar, classificar e hierarquizar o desenvolvimento das crianças como se estas constituíssem páginas em branco nas quais, pouco a pouco, fôssemos deixando as marcas mais adequadas segundo o modelo evolutivo que temos em mente. Esse tipo de entendimento só faz aumentar a incompetência da 
criança diante do adulto, desqualificando sua maneira singular de apreender o mundo que a cerca.

Ao partir de uma prática pedagógica de pretensões terapêuticas, sempre operando com estágios, fases ou etapas construídas abstratamente, tem-se a presunção do controle e da previsibilidade. Em defesa ou obsessivamente em busca de um padrão ideal, são muitas as histórias escolares de exclusão, violência simbólica e preconceitos legitimados "cientificamente" por essas opções (como a teoria da privação cultural, ou da educação compensatória, por exemplo). Paradoxal é que muitos educadores persistem em adotar determinadas referências desenvolvimentistas, mesmo vivendo, nas suas relações com as crianças, tensões demonstradoras de que tais referências não guardam nenhum tipo de correspondência com a realidade.

Estamos cotidianamente experimentando uma história real, muitas vezes brutal, da infância com que trabalhamos. Crianças que, muitas vezes, já perderam, prematuramente, a infância: pelo trabalho, pelas relações sociais opressoras, pelo consumo, pela privação do direito de ser criança e de saborear a infância, pela própria ausência de sentido da escola no seu processo de formação. Crianças portadoras de direitos freqüentemente usurpados; crianças que nos convidam a voltar à nossa própria infância, que pode também ter sido usurpada, adulterada; e que, apesar de tudo, vão construindo sua condição humana nas relações sociais, econômicas, culturais e pedagógicas que vivem a cada dia.

São essas as crianças com quem nos relacionamos, possuidoras de infâncias reais e contraditórias, infâncias cuja idealização não é mais cabível, infâncias atravessadas por todos os limites, mas também por todas as possibilidades contemporâneas. E é desse diálogo marcado por condições sociais concretas da infância que também se apresentam perspectivas de constituição de uma escola e de uma Educação Física baseadas em direitos, legitimadas pelo fato de poderem ser construídas para e com as crianças, tanto no seu nível organizacional quanto político.

Como educadores que trabalham com crianças, não podemos nos esquivar de tais reflexões. Elas precisam ocupar um lugar de centralidade na construção de nossos projetos político-pedagógicos. É ainda (e será sempre) necessário perguntar: Qual o compro- 
misso da escola com as crianças? Conseguimos aproximar nosso discurso sobre a infância de nossas práticas cotidianas com as crianças? Educamos para a submissão ou para a emancipação?

Em relação ao fazer específico da Educação Física: Quais os olhares historicamente construídos sobre a infância? Consideramos nossos alunos apenas como sujeitos que podem "vir a ser atletas", reduzindo o conteúdo das aulas a uma repetição descontextualizada de gestos, padrões de movimento ou capacidades coordenativas? Como "massinhas amorfas" a serem gradativamente modeladas pelas prescrições contidas nas apostilas de psicomotricidade? Como sujeitos indisciplinados, sem limites e hiperativos, que devem fazer Educação Física para disciplinar seus corpos e ficar mais calmos, menos agressivos e em melhores condições para frequientar a escola, respondendo às suas exigências e conteúdos preestabelecidos?

Julgamos nossos alunos incapazes para a reflexão e a compreensão sócio-histórica das práticas que realizam e, assim, em nome de uma idéia de lúdico reduzida à imagem de uma escola que deve se transformar em tempo e espaço de consumo de atividades prazerosas, ou da idéia de uma abstrata "espontaneidade" das crianças, acabamos por reduzir a aula a um brincar pelo brincar, ao passatempo, à recreação, ou mesmo ao abandono das crianças às suas próprias relações e construções?

Essas questões nos remetem a uma análise crítica de algumas proposições construídas no campo acadêmico da Educação Física. ${ }^{1}$ São proposições bastante limitadoras da presença da Educação Física na escola, na medida em que retiram das crianças o direito de acesso ao saber historicamente acumulado (o que não significa que pretendemos ater-nos a concepções conteudistas e racionalistas da escola e da educação). Esse acesso a saberes e conhecimentos não implica apenas assimilação de conteúdos, mas, fundamentalmente, a reconstrução crítica e coletiva das práticas corporais de movimento, estando aí aberta a possibilidade de sua permanente reinvenção e da constituição da escola como um projeto cultural em cuja elaboração participam diferentes atores.

Ao organizar a Educação Física para e com as crianças, precisamos, também, levar em consideração que o brincar é uma lin- 
guagem fundamental na infância, podendo se constituir em uma forma singular de produção e apropriação do conhecimento, em suas múltiplas dimensões. Inserir essa reflexão sobre o brincar nos processos de construção da cultura e produção do conhecimento significa buscar na linguagem sua plena possibilidade emancipadora, o que implica a descoberta de formas de expressão que possam ir além do recurso da palavra e se materializarem como gesto - sentido ampliado da palavra, que inclui o corpo e a memória como elementos da experiência humana de coletivamente dar significado ao mundo (Debortoli, 1999).

Finalmente destacamos que o acesso das crianças aos saberes da Educação Física precisa abranger o humano e portanto sensível, afetivo, ético, estético, elementos componentes do nosso processo de desenvolvimento, que não comporta prescrições, mas que implica identificar na criança a possibilidade humana, e portanto coletiva, de aprender e de ser. As crianças são sujeitos nesses processos e nos convidam muitas vezes a duvidar de nossas certezas sobre o jogo, a dança, o esporte, a ginástica, pois "as coisas que não têm nome são mais pronunciadas por crianças" (Barros, 2000).

Nosso desafio tem sido o de construir uma prática pedagógica fundamentada nas representações de Educação Física, de formação profissional e de infância aqui problematizadas. Para isso, torna-se fundamental considerar que a "cultura corporal de movimento", com sua diversidade de conteúdos e práticas, é também, na educação de crianças, a especificidade pedagógica da disciplina. Acreditamos, sobretudo, em uma prática de Educação Física como conhecimento escolar que se aproxima de crianças para encontrálas em seu tempo de descobertas, de invenção de conhecimentos, de vivências de infinitas formas humanas de expressão e linguagem contidas no "movimentar-se" humano.

Infancy and School Knowledge:Principles for the Construction of Physical Education Practice For and With Children

\begin{abstract}
In this article we discuss the teaching of Physical Education for Chilldren at school, and we base our reflections on university teaching, research and extension projects that we developed as professors of the Physical Education Course at UFMG. We first approach
\end{abstract}


Physical Education as a school field of knowledge and then we ask questions related to the education of teachers, identifying dillemas and the need for intervention and, in the last part, we highlight a few aspects related to infancy, here understood as a social-cultural construction and as a unique moment in the process of human growth.

KEY WORDS: Physical Education - Infancy - School.

\section{NOTA}

1. Uma importante referência na produção de uma crítica à Educação Física na infância foi a publicação do trabalho realizado em parceria pelo Núcleo de Estudos e Pesquisas de Educação Física (UFSC) e pela Secretaria Municipal de Educação de Florianópolis (1996).

\section{REFERÊNCIAS}

ARROYO, Miguel González. Ofício de mestre: imagens e auto-imagens. Petrópolis, RJ: Vozes, 2000.

BARROS, Manuel de. O livro das ignorãças. 9.ed. Rio de Janeiro: Record, 2000.

BRASIL. Ministério da Educação e do Desporto. Lei de Diretrizes e Bases da Educação Nacional (Lei nº. 9394/96). Brasília, 1996.

Ministério da Educação e do Desporto. Parâmetros Curriculares Nacionais. Brasília: MEC/SEF, 1997.

Ministério da Educação e do Desporto. Referencial Curricular Nacional para a Educação Infantil. Brasília: MEC/SEF, 1998.

DAYRELL, Juarez. (Org.). Múltiplos olhares sobre educação e cultura. Belo Horizonte: Ed. UFMG, 1996.

DEBORTOLI, José Alfredo. Com olhos de crianças: a ludicidade como dimensão fundamental da construção da linguagem e da formação humana. Licere, Belo Horizonte, v. 2, n. 1, p. 105-117, 1999. 
LINHALES, Meily A. Problemas da avaliação em Educação Física escolar: reflexões sobre a prática pedagógica. Anais do V Seminário de Educação Física Escolar. São Paulo: EEFE/USP, 1999.

VAGO, Tarcísio M. Início e fim do século XX: maneiras de fazer Educação Física na escola. Cadernos Cedes: Corpo e Educação, Campinas, n. 498, 1999a.

. Intervenção e conhecimento na escola: por uma cultura escolar de Educação Física. In: GOELLNER, Silvana. (Org.). EF/Ciências do esporte: intervenção e conhecimento. Florianópolis: CBCE, $1999 \mathrm{~b}$.

Recebido: Setembro de 2002 Aprovado: Novembro de 2002

Endereço para correspondência José Alfredo Oliveira Debortoli Rua Orlando Lima Melo, 653

Xangrilá

Contagem - Minas Gerais CEP 32186-010 